\title{
Should oral anticoagulant therapy be continued during dental extraction? A meta-analysis
}

\author{
Shuo Yang ${ }^{1}$, Quan Shi', Jinglong Liu', Jinru Li ${ }^{2}$ and Juan $\mathrm{Xu}^{1^{*}}$
}

\begin{abstract}
Background: Oral anticoagulation therapy is widely used to reduce the risks of thromboembolism. However, the therapy increases the risk of hemorrhage during the surgical procedures. The aim of this meta-analysis was to evaluate the bleeding risk of patients continuing or discontinuing oral anticoagulant therapy while undergoing dental extractions.

Methods: Six electronic databases, including PubMed, Embase, Cochrane library, Web of Science, China Biology Medicine disc (CBM), and China National Knowledge Infrastructure (CNKI), were searched in March, 2016. Relevant articles were screened by two independent reviewers under our inclusion criteria. Quality was evaluated using the Cochrane Collaboration risk of bias tool. Meta-analyses were conducted with fixed and random effects models as appropriate.

Results: Six studies (with a total of 591 patients) were included in our meta-analysis. Our results showed that there was no significant difference in the bleeding risk between patients continuing or discontinuing oral anticoagulant therapy while undergoing dental extractions (risk ratio, $1.31 ; 95 \% \mathrm{Cl}, 0.79,2.14 ; P>0.05$ ). There was also no significant difference in bleeding risk 1 day (risk ratio, $0.91 ; 95 \% \mathrm{Cl}, 0.35,2.37 ; P>0.05$ ) and 7 days (risk ratio, 1.47; $95 \% \mathrm{Cl}, 0.83,2.59 ; P>0.05)$ after the dental extraction.

Conclusion: Under current studies and evidence, it appears that patients continuing oral anticoagulant therapy do not have an increased risk of bleeding after dental extractions compared to patients who discontinue oral anticoagulant therapy.
\end{abstract}

Keywords: Oral anticoagulant therapy, Dental extraction, Bleeding, Meta-analysis

Abbreviations: NOACs, New oral anticoagulants; OAT, Oral anticoagulant therapy

\section{Background}

With the living standard gradually increasing and diet habits continuously changing, cardiovascular diseases, such as mechanical heart valve, atrial fibrillation and venous thromboembolism, have become more and more common. Millions of people receive oral anticoagulant therapy (OAT). Used to reduce thrombosis, oral anticoagulation therapy is one of the most effective prophylactic medications for preventing life-threatening events $[1,2]$. Oral anticoagulant drugs mainly include heparin, warfarin and new

\footnotetext{
* Correspondence: newxj@hotmail.com

'Department of Stomatology, Chinese People's Liberation Army General

Hospital, 28 Fuxing Road, Beijing 100853, China

Full list of author information is available at the end of the article
}

oral anticoagulants (NOACs) [3]. Heparin should be administered intravenously, and its action is to interfere with thrombin-antithrombin pathways and reduce fibrin formation. Warfarin, which is derived from 4-hydroxycoumarin, is a competitive inhibitor of vitamin $\mathrm{K}$. It is widely used all over the world [4]. New oral anticoagulants (NOACs) include factor Xa inhibitors, such as rivaroxaban, apixaban, and edoxaban, which mainly inhibit the factor Xa activity of the prothrombinase complex in the propagation phase, and factor IIa inhibitors such as dabigatran. Although their advantages included a rapid onset and a short half-life, NOACs are still not ready to completely replace conventional anticoagulants [3]. 
However, with the wide use of oral anticoagulant therapy (OAT), a major disadvantage of OAT that should receive more attention, is the increased risk of hemorrhage during surgical procedures. OATs are frequently prescribed to elder patients, who also have a higher demand for dental extraction caused by caries, periodontitis or other dental diseases. So, the problem of postoperative bleeding becomes a major concern for the dentist. Whether to continue or discontinue OAT has become a strong controversy. If OAT is continued, there is a high risk of bleeding, and if OAT is discontinued, the thromboembolic complications are potentially deadly.

Discontinuing OAT 2 or 3 days before oral surgery has been a widely used strategy for managing patients on warfarin $[5,6]$. However,the risk of postoperative bleeding apparently does not decrease, and the thromboembolic risk increases [7]. There have been documented incidences of thromboembolic events when warfarin was stopped prior to a dental procedure or a minor oral surgery [8,9]. Garcia et al. [10] published the first important prospective study on the risk of thromboembolism with a short-term interruption of OAT by reporting that the incidence of thromboembolism within a 30-day follow-up period was $0.5 \%$. Though the incidence of thromboembolism is low, the consequence may be deadly. These thromboembolic events can have devastating clinical consequences, such as an embolic stroke, which can result in major disability or death, or myocardial ischaemia, which can increase risk of death two to four fold [11]. To solve this problem, some strategies have been developed in the last few decades. These strategies include reducing the dose of the anticoagulant drugs $[12,13]$ or bridging it with heparin [14, 15]. These two methods, however, do not completely eliminate the risk of thromboembolic events, such as stroke [9]. Currently, there are a lot of publications suggest that dental extractions may be carried out with no OAT interruption if local hemostasis is adequately maintained in the OAT patients $[14,16-20]$. Nevertheless, there is still a lack of public recognition of the treatment guidelines for treating these patients. To address this controversy and to provide evidence-based recommendations, we have completed a meta-analysis. Articles on randomized controlled trials (RCTs) or controlled clinical trials (CCTs), including patients under OAT who undergo dental extractions were collected, and the postoperative bleeding was compared between patients who continued OAT and patients who discontinued OAT.

\section{Methods}

The methods for this review were based on the Cochrane Handbook for Systematic Reviews of Interventions. Throughout the whole process, the studies were assessed by 2 observers independently, and any disagreement was resolved by discussion.

\section{Database search}

A comprehensive search of the PubMed, EMBASE, Web of Science, Cochrane Library, China Biology Medicine disc (CBM), and China National Knowledge Infrastructure(CNKI) databases was conducted in March 2016. The search strategies for PubMed, EMBASE, Web of Science and Cochrane Library are shown in Table 1.

\section{Study selection}

Two reviewers independently evaluated all of the search results, and the inclusion criteria were as follows:

1. Study design-studies were designed as randomized controlled trials (RCTs) or controlled clinical trials (CCTs)

2. Participants-patients were receiving OAT and required dental extractions

3. Comparators - the postoperative bleeding between patients who continue or discontinue OAT.

4. Outcomes-postoperative bleeding (spontaneous bleeding, induced bleeding and minor bleeding)

The exclusion criteria were as follows:

1. In vitro study (laboratory studies or animal studies), case reports or letters.

2. Studies on antiplatelet medications.

3. Study outcomes were not clearly reported or the data could not be used for our meta-analysis.

\section{Data extraction}

The following parameters were extracted from each of the selected studies: the first author, country, year of publication, design type, patient characteristics, intervention method, and bleeding outcomes. The information is recorded in the table.

Because there is no accepted standardized definition of bleeding outcomes for patients undergoing surgical procedures, we aimed to use the postoperative bleeding to

Table 1 The key words, database and search result

\begin{tabular}{lll}
\hline Database & Key words & Result \\
\hline Pubmed & $\begin{array}{l}\text { (oral anticoagulant therapy OR OAT OR } \\
\text { anticoagulant*) AND (dental surgery OR dental } \\
\text { extraction* OR tooth extraction*) }\end{array}$ & 879 \\
Embase & $\begin{array}{l}\text { (oral anticoagulant therapy OR OAT OR } \\
\text { anticoagulant*) AND (dental surgery OR dental } \\
\text { extraction* OR tooth extraction*) }\end{array}$ & 634 \\
Cochrane & $\begin{array}{l}\text { (oral anticoagulant therapy OR OAT OR } \\
\text { anticoagulant*) AND (dental surgery OR dental } \\
\text { extraction* OR tooth extraction*) }\end{array}$ & 2 \\
$\begin{array}{l}\text { Web of } \\
\text { Science }\end{array}$ & $\begin{array}{l}\text { (dental surgery OR dental extraction* OR tooth } \\
\text { extraction*) AND (oral anticoagulant therapy OR }\end{array}$ & 664 \\
OAT OR anticoagulant*) & & 2179 \\
\hline Total & &
\end{tabular}


summarize the bleeding outcome after thoroughly reading the included articles. The bleeding outcomes can be defined as two processes during the follow-up days. One is the patient's own perceived bleeding, such as spontaneous bleeding that continues for more than 20 min [21] and oozing from the extraction site [7]. The other bleeding outcome is examined by doctors during the appointment, and the presence of a solid clot covering the extraction socket was considered as no bleeding, while the presence of a fresh clot that shed easily or oozing blood was considered to be positive bleeding [4].

\section{Risk of bias evaluation}

The following seven items were taken into consideration:

(1) allocation concealment, (2) random sequence generation, (3) blinding of participants and personnel, (4) blinding of outcome assessment, (5) incomplete outcome data, (6) selective reporting, and (7) other bias. The risk of bias for each item was judged as low risk, high risk, or unclear risk. The overall risk of bias for each study was evaluated by the following criteria: If the risk of bias was low for all the items, the study was of low risk. If one (or more than one) of the risk factors for bias was high for key items, the study was of high risk. If one (or more than one) of the risk factors for bias was unclear, the study had an unclear risk.

\section{Statistical analysis}

The bleeding outcomes of the included studies were combined, and a meta-analysis was performed using RevMan software (version 5.3). Subgroup analyses were performed once the included studies had the same evaluation intervals. The risk of bleeding for continuing or discontinuing OAT was expressed as a relative risk (RR) with an associated $95 \%$ CI. In addition, a chi-square and $\mathrm{I}^{2}$ test were used to estimate the degree of heterogeneity, with values of 25,50 , and $75 \%$ corresponding to the low, moderate, and high heterogeneity, respectively. Substantial heterogeneity was defined as a $\mathrm{P}$ value $<0.05$ and $\mathrm{I}^{2}>50 \%$. The fixed-effects model was applied when $\mathrm{I}^{2}<50 \%$, and the random-effects model was applied when $\mathrm{I}^{2}>50 \%$.

\section{Results}

\section{Literature search}

The search process is shown in Fig. 1. There were 968 relevant studies identified during the database search, and after the exclusion of duplication as well as titles, abstracts, and full-text screening, finally, we included six

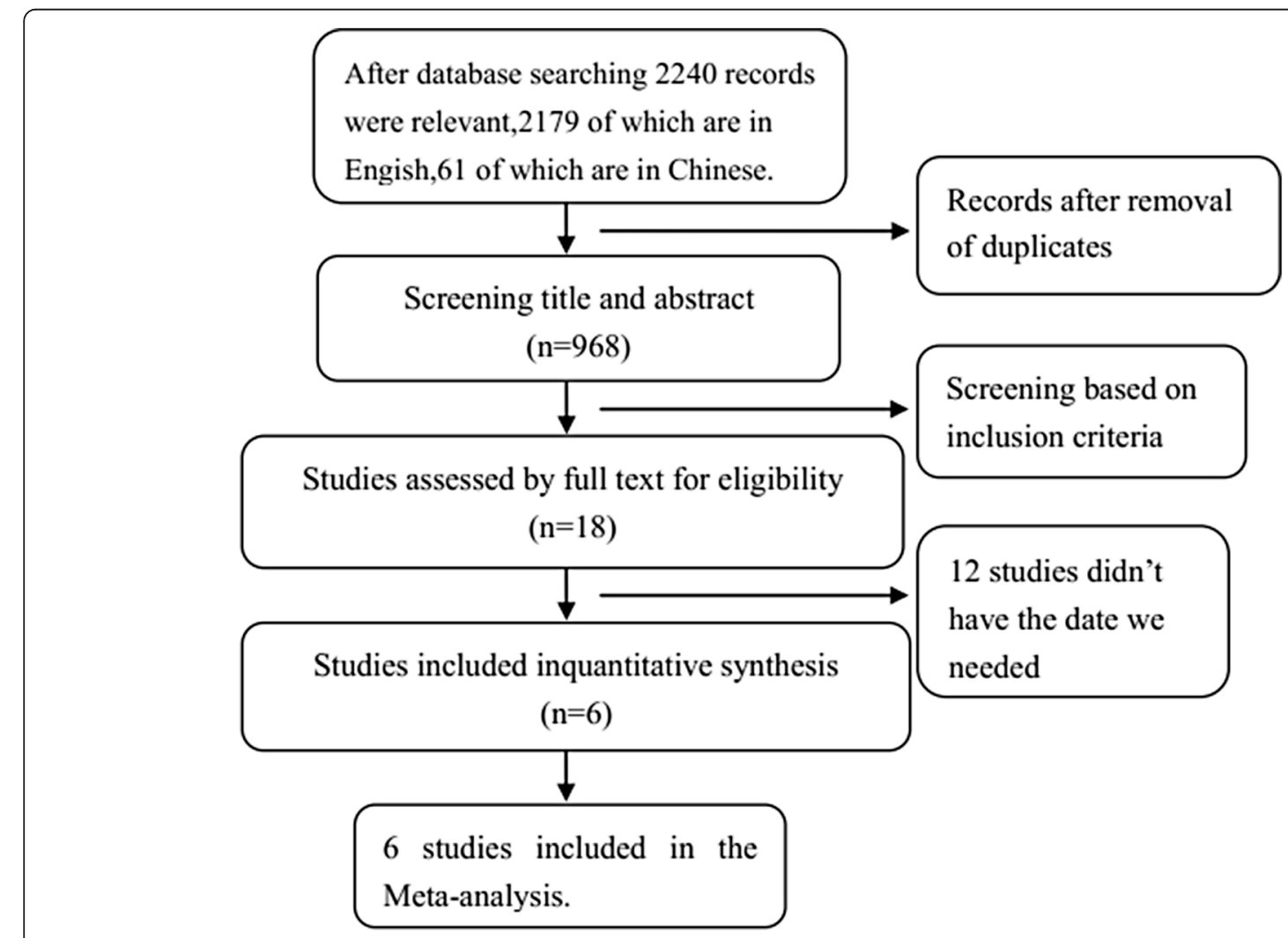

Fig. 1 Study flow diagram 
studies $[4,7,16,21-23]$ in our meta-analysis. Five of the studies are in English, and the other one [22] is in Chinese.

\section{Data extraction}

The characteristics of the selected six studies are summarized in Tables 2 and 3. The studies were published between 1993 and 2010. Four of the six studies were $\mathrm{RCT}$, and the other two were CCT. The total number of patients under OAT who received dental extractions was 581. The patients were divided into the following two groups: an OAT continued group and an OAT discontinued group. In the OAT continued group, patients did not stop their anticoagulant therapy when they needed dental extractions. In the OAT discontinued group, patients stopped their anticoagulant therapy 2 or 3 days before the dental extraction procedure and usually resumed the therapy on the same day. Four of the studies used warfarin as the anticoagulant drug, one used a vitamin $\mathrm{K}$ inhibitor and one had not report the anticoagulant. The details of the bleeding outcomes are shown in Table 3. The follow-up ranged from 1 to 7 days. The bleeding outcomes during patients' review visits were recorded if the article mentioned.

\section{Risk of bias evaluation}

The risk of bias summary is shown in Fig. 2. Of the six included studies, one [21] was judged to have a low risk of bias because all of the items had a low risk of bias. Five $[4,7,16,22,23]$ of the studies were judged to have a high risk of bias because all of the studies failed to blind participants and personnel, and three [4, 22, 23] studies failed to describe the method of randomization and had no report of the allocation concealment.

\section{Meta-analysis}

According to the postoperative bleeding outcomes, we performed a meta-analysis to compare the bleeding risk of the OAT continued and OAT discontinued groups. Six studies were included, with 314 subjects in the treated group and 277 in the control group.
The incidence of postoperative bleeding was $10.8 \%$ $(34 / 314)$ in the OAT continued group and $8.30 \%(23 /$ 277 ) in the OAT discontinued group. A fixed-effects model was applied because of the low heterogeneity across the studies. There was no significant difference in bleeding risk between the OAT continued group and OAT discontinued group $(P=0.29)$. The risk ratio was 1.31 and $95 \%$ CI $(0.79,2.14)$ (Fig. 3).

Subgroup analyses were performed when three or more studies recorded the bleeding incidence using the same evaluation intervals. Two time points ( 1 and 7 days after the operation) fit the criteria. Three studies [7, 21, 22], with 115 subjects in the treated group and 96 in the control group were included in the 1 day subgroup. The bleeding occurred in 8 of $115(6.9 \%)$ patients in the treated group and in 7 of $96(7.2 \%)$ in the control group. A fixed-effects model was applied, and there was no significant difference between the two groups $(P=$ $0.85)$. The risk ratio was 0.91 and $95 \%$ CI $(0.35,2.37)$ (Fig. 4).

Four studies [4, 16, 21, 23], with 214 subjects in the treated group and 196 in the control group were included in the 7 day subgroup. The bleeding occurred in 27 of $214(12.6 \%)$ patients in the treated group and in 17 of $196(8.7 \%)$ in the control group. A fixed-effects model was applied and there was no significant difference between the two groups $(\mathrm{P}=0.19)$. The risk ratio was 1.47 and $95 \%$ CI $(0.83,2.59)$ (Fig. 5).

\section{Discussion}

Numerous studies have reported that OAT reduces the risks of thromboembolism significantly [24, 25]. Other studies have documented that serious embolic complications, including death, are three times more likely to occur in patients whose anticoagulant therapy was interrupted, compared to patients with bleeding complications associated with anticoagulation [26]. For oral surgery procedures, no case of lethal postoperative bleeding in patients who continued OAT has been reported [16, 26], whereas several fatal thromboembolic events after stopping OAT for dental extractions have

Table 2 Characteristics of included studies

\begin{tabular}{|c|c|c|c|c|c|}
\hline Study & Country & No. $(T / C)^{a}$ & Design & Anticoagulants & Average age (mean \pm SD or mean (range)) \\
\hline Borea (1993) [21] & Italy & $30(15 / 15)$ & $\mathrm{RCT}$ & $N R^{b}$ & $\mathrm{~T}: 62.7 \pm 6.1 \mathrm{C}: 61.1 \pm 10$ \\
\hline Gaspar (1997) [23] & Israel & $47(32 / 15)$ & $\mathrm{CCT}$ & Vitamin K inhibitor & $\mathrm{T}: 61.1(34-85) \mathrm{C}: 53.4(35-72)$ \\
\hline Devani (1998) [7] & UK & $65(33 / 32)$ & $\mathrm{CCT}$ & Warfarin & $\mathrm{T}: 62.3(30-82) \mathrm{C}:$ 61.3(32-81) \\
\hline Evans (2002) [16] & UK & $109(57 / 52)$ & $\mathrm{RCT}$ & Warfarin & $\mathrm{T}: 67(36-92) \mathrm{C}: 66$ (30-93) \\
\hline \multirow[t]{2}{*}{ Al-Mubarak (2007) [4] } & Saudi Arabia & 214(110/114) & $\mathrm{RCT}$ & Warfarin & $\mathrm{T}: 51.7 \pm 14.753 .1 \pm 13.7$ \\
\hline & & & & & C: $52.3 \pm 14.348 .7 \pm 13.1$ \\
\hline Duan XQ (2010) [22] & China & $116(67 / 49)$ & $\mathrm{RCT}$ & warfarin & $\mathrm{T:}: 59.5 \pm 12.6 \mathrm{C}: 61.5 \pm 11.3$ \\
\hline
\end{tabular}

${ }^{a} T$ treatment group, continue oral anticoagulant therapy group, $C$ control group, discontinue oral anticoagulant therapy group 
Table 3 Characteristics of included studies

\begin{tabular}{|c|c|c|c|c|c|c|}
\hline Study & Group & INR (mean/range) & Intervention method & Number of extraction & $\begin{array}{l}\text { Follow } \\
\text { up }\end{array}$ & Bleeding outcomes \\
\hline $\begin{array}{l}\text { Borea } \\
(1993) \\
{[21]}\end{array}$ & $\begin{array}{l}\text { T: continued OAT. } \\
\text { C: discontinued OAT. }\end{array}$ & $\begin{array}{l}\mathrm{T}: 3-4.5 \\
\mathrm{C}: 1.5-2.5\end{array}$ & $\begin{array}{l}\text { T: Sutures and TA } \\
\text { irrigation at surgery } \\
\text { and MS for } 7 \text { day. } \\
\text { C: Sutures and } \\
\text { physiologic irrigation } \\
\text { at surgery and MS for } \\
7 \text { days. }\end{array}$ & Single dental & 7 days & $\begin{array}{l}\text { Day 1: } \\
\text { Spontaneous bleedings } \\
\text { T: } 1 / 15 \text { C:2/15 } \\
\text { Induced bleedings } \\
\text { T:1/15 C:0/15 } \\
\text { Day } 2 \text { to day } 7 \text { : none }\end{array}$ \\
\hline $\begin{array}{l}\text { Evans } \\
(2002) \\
{[16]}\end{array}$ & $\begin{array}{l}\text { T: continued OAT. } \\
\text { C: discontinued OAT } 2 \text { days } \\
\text { before extractions and } \\
\text { resumed on the same day. }\end{array}$ & $\begin{array}{l}\text { T: } 2.5(1.2-4.7) \\
\text { C: } 1.6(1.2-2.3)\end{array}$ & $\begin{array}{l}\text { All groups: } \\
\text { Oxycellulose dressing } \\
\text { and sutures for all } \\
\text { patients. }\end{array}$ & $\begin{array}{l}\text { T: } 2(1-7) \\
\text { C: } 3(1-9)\end{array}$ & 7 days & $\begin{array}{l}\text { Postoperative bleeding } \\
\mathrm{T}: 15 / 57 \mathrm{C}: 7 / 52\end{array}$ \\
\hline $\begin{array}{l}\text { Devani } \\
\text { (1998) [7] }\end{array}$ & $\begin{array}{l}\text { T: continued OAT. } \\
\text { C: discontinued OAT } 2 \text { days } \\
\text { before extractions. }\end{array}$ & $\begin{array}{l}\mathrm{T}: 2.7(2.2-3.9) \\
\mathrm{C}: 1.6(1.2-2.1)\end{array}$ & $\begin{array}{l}\text { All groups: } \\
\text { Placing haemostatic } \\
\text { pack and sutures. }\end{array}$ & $\begin{array}{l}\text { T: } 2.1(1-9) \\
\text { C: } 2(1-9)\end{array}$ & 5 days & $\begin{array}{l}\text { Minor bleeding: } \\
\text { Day } 1 \text { T:0/33 C:0/32 } \\
\text { Day } 2 \text { T:0/33 C:1/32 } \\
\text { Day } 3 \text { T:1/33 C:0/32 } \\
\text { Day } 4 \text { to day 5:none }\end{array}$ \\
\hline $\begin{array}{l}\text { Gaspar } \\
(1997) \\
{[23]}\end{array}$ & $\begin{array}{l}\text { T: continued OAT } \\
\text { C: discontinued OAT } 3 \text { days } \\
\text { before and resumed the same } \\
\text { day }\end{array}$ & $\begin{array}{l}\text { T: } 2.5(1.9-3.5) \\
\text { C: } 1.4(1.3-1.9)\end{array}$ & $\begin{array}{l}\text { All groups: } \\
\text { Sutures and TA } \\
\text { irrigation at surgery } \\
\text { and MS for } 2 \text { min.MS } \\
\text { for } 7 \text { days } \\
\text { postoperativedays }\end{array}$ & $N R$ & 7 days & $\begin{array}{l}\text { Postoperative bleeding } \\
\mathrm{T}: 2 / 32 \mathrm{C}: 1 / 15\end{array}$ \\
\hline $\begin{array}{l}\text { Al- } \\
\text { Mubarak } \\
(2007)[4]\end{array}$ & $\begin{array}{l}\text { T: continued OAT (group2 no } \\
\text { sutures,group4 sutures). } \\
\text { C: discontinued OAT } 2 \text { days } \\
\text { before and resumed } 12 \mathrm{~h} \\
\text { after dental extractions } \\
\text { (group1 no sutures, group } 3 \\
\text { sutures). }\end{array}$ & $\begin{array}{l}\text { T: } 1.85(1.4-2.3) \\
\text { C:2.55(1.9-3.1) }\end{array}$ & $\begin{array}{l}\text { Local pressure (all) and } \\
\text { sutures (group } 3 \text { and } 4 \text { ). }\end{array}$ & $\begin{array}{l}\text { All patients range } 1-5 \text {, } \\
\text { single extraction }(63.3) \\
\text { two teeth }(25 \%) \text {, three } \\
\text { teeth }(7.5 \%) \text { four teeth } \\
(3.3 \%) \text { and five teeth } \\
(0.8 \%) .\end{array}$ & 7 days & $\begin{array}{l}\text { Postoperative bleeding } \\
\mathrm{T}: 8 / 110 \text { C:7/114 }\end{array}$ \\
\hline $\begin{array}{l}\text { Duan XQ } \\
(2010) \\
{[22]}\end{array}$ & $\begin{array}{l}\text { T: continued OAT. } \\
\text { C: discontinued OAT } 3 \text { days } \\
\text { before and resumed the next } \\
\text { day. }\end{array}$ & ALL: $1.80-2.67$ & $\begin{array}{l}\text { All groups: } \\
\text { Local pressure and } \\
\text { sutures. }\end{array}$ & $\begin{array}{l}\mathrm{T}: 1.5(1-5) \\
\mathrm{C}: 1.3(1-5)\end{array}$ & 1 day & $\begin{array}{l}\text { Postoperative bleeding } \\
\mathrm{T}: 6 / 67 \text { C:5/49 }\end{array}$ \\
\hline
\end{tabular}

OAT oral anticoagulant therapy, $T$ treatment group, $C$ control group, INR international normalized ratio, $M W$ mouthwash, $T A$ tranexamic acid, $N R$ not report

occurred $[8,27]$. Nevertheless, there is still a lack of consensus regarding preoperative alteration of the anticoagulant regimen to prepare OAT patients for dental extractions.

\section{Summary of results}

The results of our meta-analysis revealed that patients continuing oral anticoagulant therapy do not have an increased risk of bleeding after dental extraction compared to patients who discontinue oral anticoagulant therapy. However, the follow-up dates were not the same between these studies. One of the studies [22] only reported the first day bleeding outcome, and one study [7] followed-up for 5 days with a detailed record of everyday situations. The other four studies $[4,16,21,23]$ followed up for 7 days after the dental extraction, but three studies only mentioned the total number of bleeding events and the remaining one recorded everyday situations. Subgroup analyses were performed since three of the included studies $[7,21,22]$ recorded the bleeding outcome 1 day after surgery, and four included studies $[4,16,21$,
23] collected measurements for 7 days after the surgery. The results were consistent with the previous results. There was no significant difference in bleeding risk between the OAT continued group and the OAT discontinued group 1 and 7 days after the surgery. Of all the studies, none of these patients suffered serious bleeding, and the bleeding was easily controlled by patients at home or controlled with local measures during their visit to the hospital. No thromboembolic event was reported in these studies, whether OAT was continued or not. However, this outcome could be a result of the short follow-up period of these studies (from 1 to 7 days), which made it difficult assess the thromboembolism risk in patients who discontinued OAT.

All of the 6 included studies came to the conclusion that OAT patients who do not discontinue the anticoagulant medication do not have a significantly higher risk of postoperative bleeding than OAT patients who stop the therapy. Some of the studies mentioned the importance of international normalized ratio (INR) and hemostatic procedures. INR has been used as a 


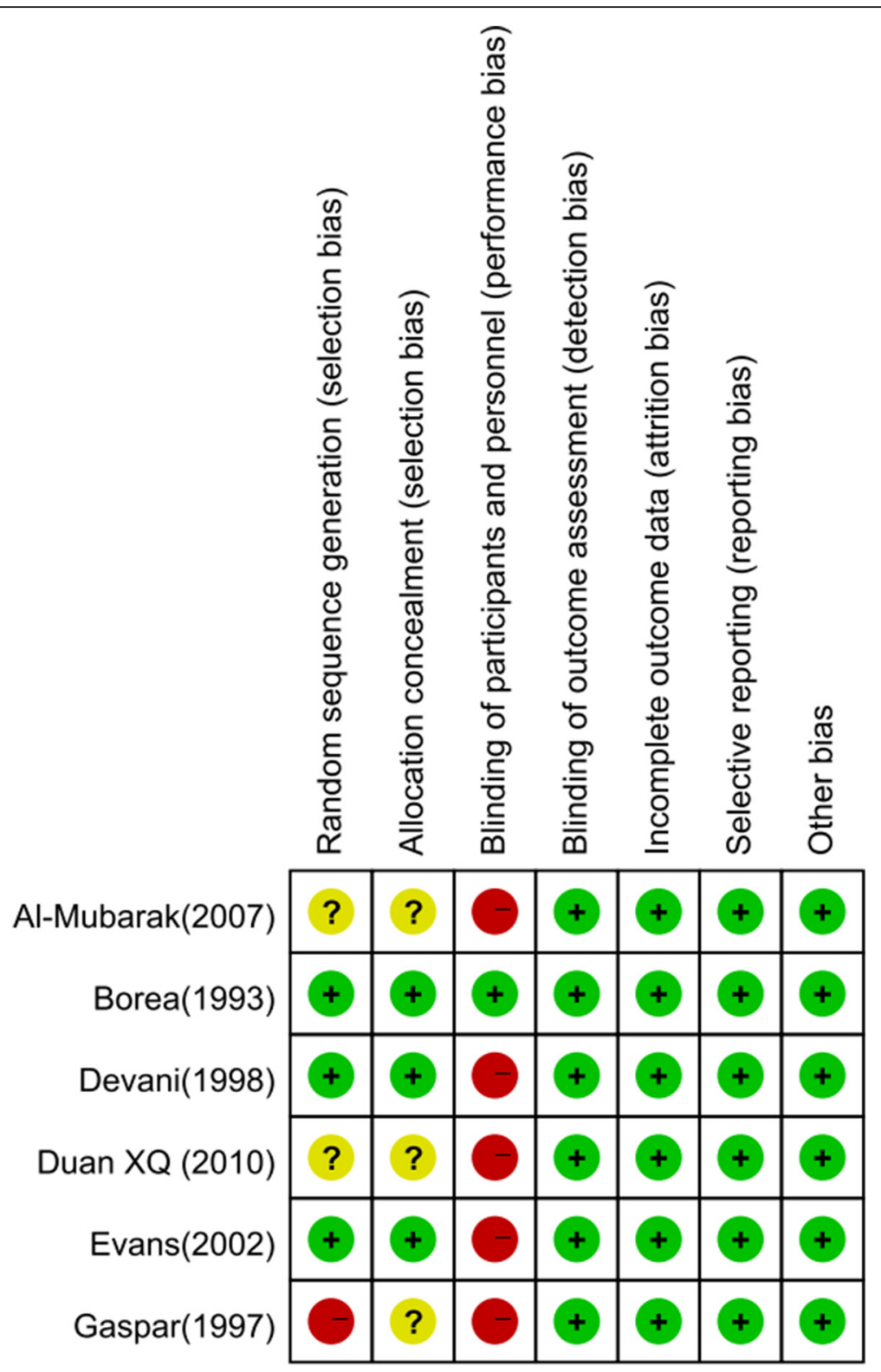

Fig. 2 Risk of bias of the studies. Summary of risk of bias for included studies. Green indicates a low risk of bias, yellow indicates an unclear risk of bias, and red indicates a high risk of bias

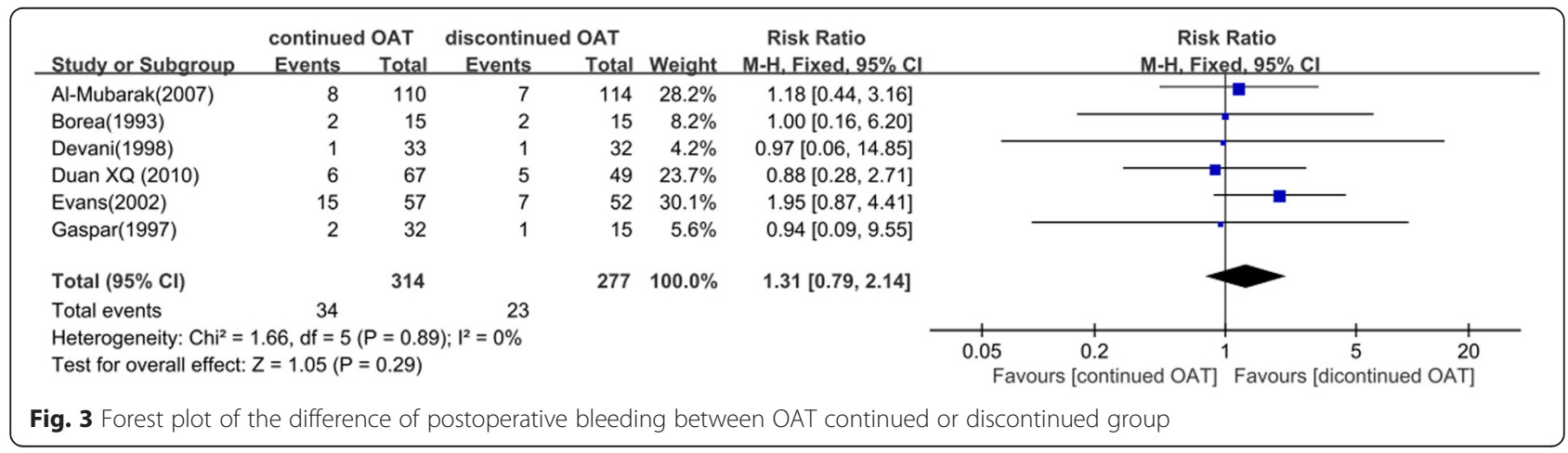




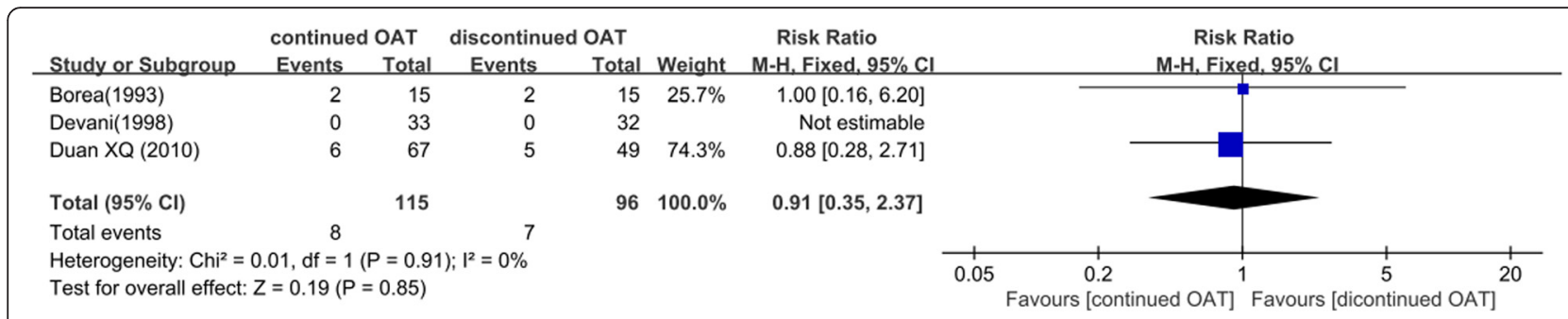

Fig. 4 Forest plot of the difference of postoperative bleeding between OAT continued or discontinued group 1 day after the surgery

recommendation for monitoring patients' oral anticoagulant therapy. For stroke prevention in atrial fibrillation patients, oral anticoagulation therapy that is dose adjusted to maintain an INR range of 2.0 to 3.0 is associated with a $64 \%$ reduction in the risk of stroke compared to placebo [28]. And in patients suffering an acute venous thromboembolism (either deep vein thrombosis or pulmonary embolism), adjusted-dose OAT use significantly reduces the risk of recurrence of thrombotic events with a target INR range of 2.0-3.0. [29]. According to meta-analyses of atrial fibrillation or mixed populations assessing INR control and associated events [30], more than half of all thromboembolic events occurred when patients have an INR $<2.0$. Besides, the INR has a safe range before surgical procedures. This "safe range" is controversial because some experts recommended an INR of $\leq 3$ [17, 31], whereas others suggest an INR of $\leq 4$ $[32,33]$ as safe for dental extractions. An INR above 5 has been shown to be an unacceptable risk for postoperative bleeding [34]. However, none of the included patients had an INR of more than 5. Most of the patients had an INR no higher than 4, as shown in Table 3. Next to monitoring the INR, it is recommended to take a special care of patients with renal dysfunction. Given the renal excretion of drugs, renal dysfunction may result in a higher incidence of bleeding associated with oral anticoagulation [35, 36]. A variety of local hemostatic measures are used in oral surgeries, including sutures, local compression, adjuvants (such as fibrin and histoacryl glue), local antifibrinolytic solutions, collagen fleeces, acrylic splints, gelatin sponges and so on [37, 38]. Placing hemostatic, physiological or tranexamic acid irrigation and mouthwash were used in our included studies. However, one of the included studies [4] showed that suturing played no significant role in bleeding status. In their study, patients with sutures showed a higher incidence of bleeding than patients without sutures. This outcome might be caused by the mode of suturing that further traumatizes the soft tissue. Four of the included studies $[7,16,21,23]$ used local hemostatic measures, except for local compression and sutures. The effectiveness of these measures was worth studying.

\section{Limitations}

There were some limitations in the included studies. Only one of the six included studies was judged to have a low risk of bias, and the absence of randomization may predispose the analysis to a risk of selection bias and possible confounding effects [39]. Some studies were carried out with limited patient numbers $[21,23]$ and, as with all meta-analyses, there may be studies published in other languages or unpublished studies that we were not able to access. Additionally, the INR differed between different studies which influenced the bleeding outcomes. Patients with a low INR were less likely to suffer bleeding than patients with a higher INR. Other factors, such as gingival health, numbers and the complexity of the tooth extractions, the surgical skills, anesthesia type, material and suture technique, local hemostatic measures, and the use of anticoagulants differed from one study to another or were not reported. This heterogeneity limited the scientific evidence that could be obtained for this review.

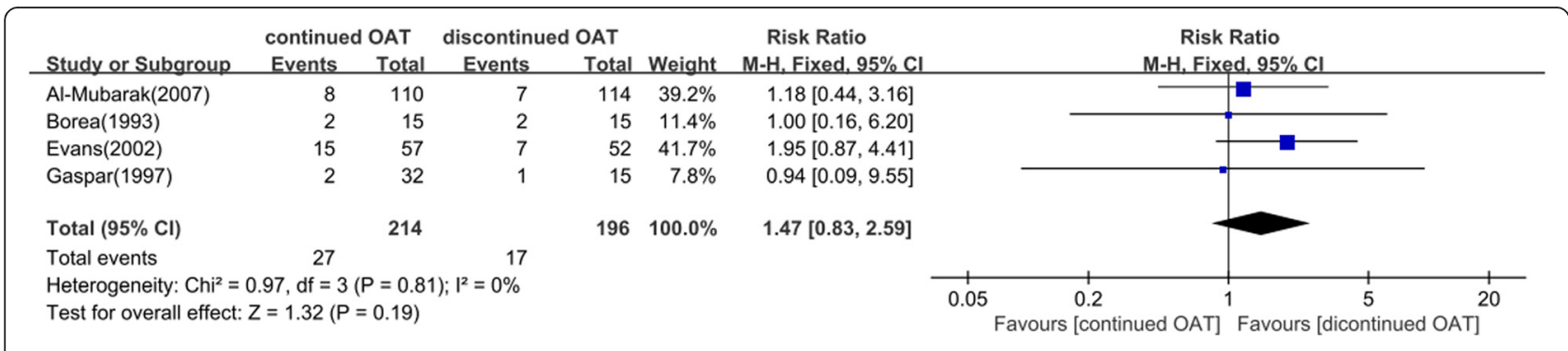

Fig. 5 Forest plot of the difference of postoperative bleeding between OAT continued or discontinued group 7 days after the surgery 


\section{Conclusion}

Under current studies and evidence, the results of our meta-analysis revealed that patients continuing oral anticoagulant therapy do not increase the risk of bleeding after dental extractions compared to patients who discontinue oral anticoagulant therapy. However, with the limited number of included studies and the risk of bias, well-designed RCTs should be included with a larger sample size as well as specific inclusion and exclusion criteria. Moreover, it would be better if the bleeding outcomes had a reporting standard. This standardization would enhance the comparability of studies based on identical outcome measurements, which would help to establish guidelines for dentists who treat these patients with complex medical needs.

\section{Acknowledgements}

This work was supported by a grant from the National Natural Science Foundation of China emergency management project (No. 81541111) and Clinical scientific research fund (No.320.6750.15029) from Wu Jieping Medical Foundation.

\section{Availability of data and materia}

The authors declare that materials described in the manuscript, including all relevant raw data, will be freely available to any scientist wishing to use them for non-commercial purposes, without breaching participant confidentiality. We ensure that our datasets are either deposited in publicly available repositories (where available and appropriate) or presented in the main manuscript or additional supporting files, in machine-readable format (such as spreadsheets rather than PDFs) whenever possible.

\section{Authors' contributions}

YS carried out the literature research and drafted the manuscript. YS, SQ, LJL and LJR gathered the information and performed the statistical analysis. $\mathrm{XJ}$ is the Corresponding author and she designed this meta-analysis, and helped to draft the manuscript. All authors read and approved the final manuscript.

\section{Competing interests}

The authors declare that they have no competing interests.

\section{Consent for publication}

Not applicable.

\section{Ethics approval and consent to participate}

Not applicable.

\section{Author details}

'Department of Stomatology, Chinese People's Liberation Army General Hospital, 28 Fuxing Road, Beijing 100853, China. ${ }^{2}$ Department of Stomatology, Chinese People's Liberation Army 322 Hospital, 2 Yunzhong Road, Datong 037000, China.

Received: 22 June 2016 Accepted: 12 August 2016

Published online: 26 August 2016

\section{References}

1. Mok CK, Boey J, Wang R, Chan TK, Cheung KL, Lee PK, Chow J, Ng RP, Tse TF. Warfarin versus dipyridamole-aspirin and pentoxifylline-aspirin for the prevention of prosthetic heart valve thromboembolism: a prospective randomized clinical trial. Circulation. 1985:72:1059-63.

2. Stein PD, Collins JJ, Kantrowitz A. Antithrombotic therapy in mechanical and biological prosthetic heart valves and saphenous vein bypass grafts. Chest. 1986:89:46S-53.

3. CADTH Therapeutic Reviews. Recommendations for antithrombotic agents for the prevention of stroke and systemic embolism in patients with atrial fibrillation. Ottawa: Canadian Agency for Drugs and Technologies in Health; 2013.

4. Al-Mubarak S, Al-Ali N, Abou-Rass M, Al-Sohail A, Robert A, Al-Zoman K, AlSuwyed A, Ciancio S. Evaluation of dental extractions, suturing and INR on postoperative bleeding of patients maintained on oral anticoagulant therapy. Br Dent J. 2007:203:E15. 410-411.

5. Mulligan $\mathrm{R}$, Weitzel $\mathrm{KG}$. Pretreatment management of the patient receiving anticoagulant drugs. J Am Dent Assoc. 1988;117:479-83.

6. Wahl MJ. Demystifying medical complexities. J Calif Dent Assoc. 2000;28:510-8.

7. Devani $P$, Lavery KM, Howell CJ. Dental extractions in patients on warfarin: is alteration of anticoagulant regime necessary? Br J Oral Maxillofac Surg. 1998:36:107-11.

8. Wahl MJ. Dental surgery in anticoagulated patients. Arch Intern Med. 1998; 158:1610-6.

9. Dunn AS, Turpie AG. Perioperative management of patients receiving oral anticoagulants: a systematic review. Arch Intern Med. 2003;163:901-8.

10. Garcia DA, Regan S, Henault LE, Upadhyay A, Baker J, Othman M, Hylek EM. Risk of thromboembolism with short-term interruption of warfarin therapy. Arch Intern Med. 2008;168:63-9.

11. Kaplan RC, Tirschwell DL, Longstreth WJ, Manolio TA, Heckbert SR, Lefkowitz D, El-Saed A, Psaty BM. Vascular events, mortality, and preventive therapy following ischemic stroke in the elderly. Neurology. 2005;65(6):835-42.

12. Johnson WT, Leary JM. Management of dental patients with bleeding disorders: review and update. Oral Surg Oral Med Oral Pathol. 1988;66:297-303.

13. DeClerck D, Vinckier F, Vermylen J. Influence of anticoagulation on blood loss following dental extractions. J Dent Res. 1992;71:387-90.

14. Souto JC, Oliver A, Zuazu-Jausoro I, Vives A, Fontcuberta J. Oral surgery in anticoagulated patients without reducing the dose of oral anticoagulant: a prospective randomized study. J Oral Maxillofac Surg. 1996;54:27-32. 323.

15. Johnson-Leong C, Rada RE. The use of low-molecular-weight heparins in outpatient oral surgery for patients receiving anticoagulation therapy. J Am Dent Assoc. 2002:133:1083-7.

16 Evans IL, Sayers MS, Gibbons AJ, Price G, Snooks H, Sugar AW. Can warfarin be continued during dental extraction? Results of a randomized controlled trial. Br J Oral Maxillofac Surg. 2002;40:248-52.

17 Blinder D, Manor Y, Martinowitz U, Taicher S, Hashomer T. Dental extractions in patients maintained on continued oral anticoagulant: comparison of local hemostatic modalities. Oral Surg Oral Med Oral Pathol Oral Radiol Endod. 1999;88:137-40.

18 Blinder D, Manor Y, Martinowitz U, Taicher S. Dental extractions in patients maintained on oral anticoagulant therapy: comparison of INR value with occurrence of postoperative bleeding. Int J Oral Maxillofac Surg. 2001;30:518-21.

19 Al-Belasy FA, Amer MZ. Hemostatic effect of n-butyl-2-cyanoacrylate (histoacryl) glue in warfarin-treated patients undergoing oral surgery. J Oral Maxillofac Surg. 2003;61:1405-9.

20 Carter G, Goss A, Lloyd J, Tocchetti R. Tranexamic acid mouthwash versus autologous fibrin glue in patients taking warfarin undergoing dental extractions: a randomized prospective clinical study. J Oral Maxillofac Surg. 2003:61:1432-5.

21 Borea G, Montebugnoli L, Capuzzi P, Magelli C. Tranexamic acid as a mouthwash in anticoagulant-treated patients undergoing oral surgery. An alternative method to discontinuing anticoagulant therapy. Oral Surg Oral Med Oral Pathol. 1993;75:29-31.

22 Duan XQ, Lv YL, Zuo J, Gong LN, Wang J, Meng X. Clinical studies in patients with artificial heart valve replacement surgery tooth extraction. Beijing J Stomatol. 2010;18:332-4.

23 Gaspar R, Brenner B, Ardekian L, Peled M, Laufer D. Use of tranexamic acid mouthwash to prevent postoperative bleeding in oral surgery patients on oral anticoagulant medication. Quintessence Int. 1997;28:375-9.

24 Doraiswamy VA, Slepian MJ, Gesheff MG, Tantry US, Gurbel PA. Potential role of oral anticoagulants in the treatment of patients with coronary artery disease: focus on dabigatran. Expert Rev Cardiovasc Ther. 2013:11:1259-67.

25 Agnelli G, Becattini C. Risk assessment for recurrence and optimal agents for extended treatment of venous thromboembolism. Hematology Am Soc Hematol Educ Program. 2013;2013:471-7.

26 Wahl MJ. Myths of dental surgery in patients receiving anticoagulant therapy. J Am Dent Assoc. 2000;131:77-81.

27 Yasaka M, Naritomi H, Minematsu K. Ischemic stroke associated with brief cessation of warfarin. Thromb Res. 2006;118:290-3.

28 Hart RG, Pearce LA, Aguilar MI. Meta-analysis: antithrombotic therapy to prevent stroke in patients who have nonvalvular atrial fibrillation. Ann Intern Med. 2007;146(12):857-67.

29 Kearon C, Akl EA, Ornelas J, Blaivas A, Jimenez D, Bounameaux H, Huisman M, King CS, Morris TA, Sood N, et al. Antithrombotic Therapy for VTE Disease: CHEST Guideline and Expert Panel Report. Chest. 2016;149(2):315-52. 
30 Erkens PM, Ten $\mathrm{CH}$, Buller HR, Prins MH. Benchmark for time in therapeutic range in venous thromboembolism: a systematic review and meta-analysis. Plos One. 2012; $7(9):$ :e42269.

31 Campbell JH, Alvarado F, Murray RA. Anticoagulation and minor oral surgery: should the anticoagulation regimen be altered? J Oral Maxillofac Surg. 2000:58:131-5. 135-136.

32 Cieslik-Bielewska A, Pelc R, Cieslik T. Oral surgery procedures in patients on anticoagulants. Preliminary report. Kardiol Pol. 2005;63:137-40. 141.

33 Lippert S, Gutschik E. Views of cardiac-valve prosthesis patients and their dentists on anticoagulation therapy. Scand J Dent Res. 1994;102(3):168-71.

34 Beirne OR, Koehler JR. Surgical management of patients on warfarin sodium. J Oral Maxillofac Surg. 1996;54:1115-8.

35 Piccini JP, Stevens SR, Chang Y, Singer DE, Lokhnygina Y, Go AS, Patel MR, Mahaffey KW, Halperin JL, Breithardt G, et al. Renal dysfunction as a predictor of stroke and systemic embolism in patients with nonvalvular atrial fibrillation: validation of the R(2)CHADS(2) index in the ROCKET AF (Rivaroxaban Once-daily, oral, direct factor Xa inhibition Compared with vitamin $\mathrm{K}$ antagonism for prevention of stroke and Embolism Trial in Atrial Fibrillation) and ATRIA (AnTicoagulation and Risk factors In Atrial fibrillation) study cohorts. Circulation. 2013;127(2):224-32.

36 Hart RG, Eikelboom JW, Ingram AJ, Herzog CA. Anticoagulants in atrial fibrillation patients with chronic kidney disease. Nat Rev Nephrol. 2012;8(10):569-78.

37 Rakocz M, Mazar A, Varon D, Spierer S, Blinder D, Martinowitz U. Dental extractions in patients with bleeding disorders. The use of fibrin glue. Oral Surg Oral Med Oral Pathol. 1993;75:280-2.

38 Bajkin BV, Popovic SL, Selakovic SD. Randomized, prospective trial comparing bridging therapy using low-molecular-weight heparin with maintenance of oral anticoagulation during extraction of teeth. J Oral Maxillofac Surg. 2009;67:990-5.

39 Fleming PS, Lynch CD, Pandis N. Randomized controlled trials in dentistry: common pitfalls and how to avoid them. J Dent. 2014;42:908-14.

\section{Submit your next manuscript to BioMed Central and we will help you at every step:}

- We accept pre-submission inquiries

- Our selector tool helps you to find the most relevant journal

- We provide round the clock customer support

- Convenient online submission

- Thorough peer review

- Inclusion in PubMed and all major indexing services

- Maximum visibility for your research

Submit your manuscript at www.biomedcentral.com/submit

) Biomed Central 